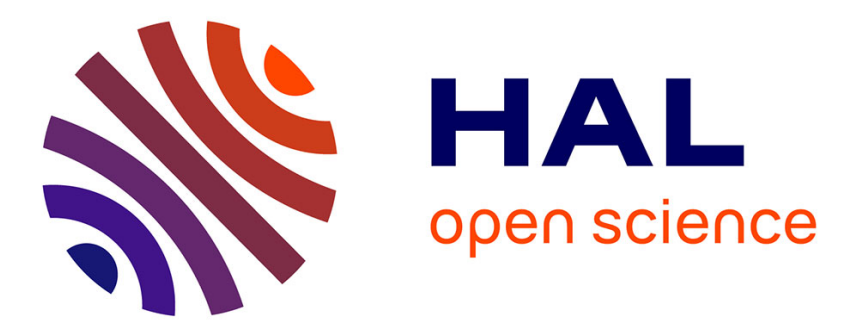

\title{
An experimental and modeling study of the oxidation of n-heptane, ethylbenzene, n-butylbenzene in a jet-stirred reactor at pressures up to 10 bar
}

Olivier Herbinet, Benoit Husson, Hervé Le Gall, Frederique Battin-Leclerc

\section{- To cite this version:}

Olivier Herbinet, Benoit Husson, Hervé Le Gall, Frederique Battin-Leclerc. An experimental and modeling study of the oxidation of n-heptane, ethylbenzene, n-butylbenzene in a jet-stirred reactor at pressures up to 10 bar. International Journal of Chemical Kinetics, 2020, 10.1002/kin.21417. hal-03196696

\section{HAL Id: hal-03196696 \\ https://hal.science/hal-03196696}

Submitted on 13 Apr 2021

HAL is a multi-disciplinary open access archive for the deposit and dissemination of scientific research documents, whether they are published or not. The documents may come from teaching and research institutions in France or abroad, or from public or private research centers.
L'archive ouverte pluridisciplinaire HAL, est destinée au dépôt et à la diffusion de documents scientifiques de niveau recherche, publiés ou non, émanant des établissements d'enseignement et de recherche français ou étrangers, des laboratoires publics ou privés. 


\title{
An experimental and modeling study of the oxidation of $n$-heptane, ethylbenzene, $n$-butylbenzene in a jet- stirred reactor at pressures up to 10 bar
}

\author{
Olivier Herbinet ${ }^{1, *}$, Benoit Husson ${ }^{1}$, Hervé Le Gall1, Frédérique Battin- \\ Leclerc $^{1}$
}

1Université de Lorraine, CNRS, LRGP, F-54000 Nancy, France

Published in the International Journal of Chemical Kinetics, 2020, 52, 1006-1021

\begin{abstract}
In the context of better understanding pollutant formation from internal combustion engines, new experimental speciation data were obtained in a high-pressure jet-stirred reactor for the oxidation of three molecules, which are considered in surrogates of Diesel fuel, $n$-heptane, ethylbenzene, $n$-butylbenzene. These experiments were performed at pressures up to $10 \mathrm{bar}$, at temperatures ranging from 500 to $1100 \mathrm{~K}$ and for a residence time of $2 \mathrm{~s}$. Based on results previously obtained close to atmospheric pressure for the same molecules, the pressure effect on fuel conversion and product selectivity was discussed. In addition, for the three fuels, the experimental temperature dependence of species mole fractions were compared with simulations using recent literature models with generally a good agreement. For $n$-heptane, the obtained experimental data, at 10 bar for stoichiometric mixtures, included the temperature dependence of the mole fractions of the reactants and those of 21 products. Interestingly, the formation of species previously identified as $C_{7}$ diones was found significantly enhanced at 10 bar compared to lower pressures. The oxidation of ethyl- and $n$-butylbenzene was investigated at 10 bar for equivalence ratios of $0.5,1$ and 2. The obtained experimental data included the temperature dependence of the mole fractions of the reactants and those of 13 products for the $\mathrm{C}_{8}$ fuels and of 19 products for the $\mathrm{C}_{10}$ one. For ethylbenzene under stoichiometric conditions, the pressure dependence (from 1 to 10 bar) of species mole fraction was also recorded and compared with simulations with more deviations obtained than for temperature dependence. For both aromatic reactants, a flow rate analysis was used to discuss the main pressure influence on product selectivities.
\end{abstract}

Keywords: jet-stirred reactor; oxidation; $n$-heptane; ethylbenzene; $n$-butylbenzene; pressure effect study.

${ }^{*}$ Corresponding author information:

Olivier HERBINET

E-mail: olivier.herbinet@univ-lorraine.fr 


\section{Introduction}

Diesel fuels used in compression-ignition engines are complex mixtures containing hundreds of species. They are composed of a broad range of hydrocarbons obtained from the distillation of crude oil and also of oxygenated molecules used as additives 1,2 . There are three main classes of species found in petroleum-based diesel fuels: $n$ - and iso-paraffins, naphthenes and aromatics. The number of carbon atoms ranges from 10 to 22 with an average around 14-15 ${ }^{1}$. Each of the three molecular classes represents about one-third of diesel fuels according to the origin and treatments of crude oil. The aromatic compounds found in diesel fuels are usually monoaromatics with one or several side alkyl chains. Alkylated double ringed compounds (e.g., $\alpha$-methyl-naphthalene) can also be found in significant concentrations ${ }^{2,3}$.

The present paper first focuses on the oxidation of $n$-heptane at pressures up to 10 bar in a JetStirred Reactor (JSR). This molecule is usually considered as a surrogate of $n$-paraffins. Afterwards, the paper continues with two compounds representative of the monoaromatics present in Diesel fuels, ethylbenzene and $n$-butylbenzene.

Since $n$-heptane has often been considered as a surrogate molecule for gasolines and Diesel fuels, there has been a lot of kinetic studies related to its combustion in various experimental devices as presented in review papers 4,5 . Focusing only on the work carried out in JSRs, this was pioneered by Dagaut et al. from 1994 6,7. These authors measured species mole fraction at temperatures from 550 to $1150 \mathrm{~K}$ and pressures from 1 to 40 bar for a stoichiometric mixture under isothermal conditions obtained thought a high dilution. These results put in evidence a significant Negative Temperature Coefficient (NTC) behavior. This work was closely followed by that of Ciajolo and d'Anna ${ }^{8}$, but under non-isothermal conditions. More recently, $n$-heptane oxidation was again investigated in a JSR working under isothermal conditions. These experiments were carried out at 1 bar under the same temperature range as [6,7], but with an increased range of detected products 9,10 , and for lean and rich mixtures (equivalence ratios from 0.25 to 4) ${ }^{11,12}$. The paper of Zhang et al. ${ }^{11}$ also presented the most recent version of the Galway model for the oxidation of this $\mathrm{C}_{7}$ alkane. This model was based on reaction rate rules revisited using theoretical calculations and was validated using data obtained in JSRs, but also using ignition delays measured in shock tubes. The present paper describes new data obtained in a JSR working under isothermal conditions, at 10 bars for stoichiometric mixtures. Comparisons are presented with the older data of Dagaut et al. ${ }^{7}$ and with modelling using the recent model of Zhang et al. ${ }^{11}$.

Kinetic investigations about ignition and oxidation product formation from monoaromatics with a single alkyl chain have been the subject of many experimental and modeling studies. Most of these studies concern ethylbenzene ${ }^{13-25}$ and $n$-propylbenzene 13,14,19,26-35. There are much less data about iso-propyl-benzene ${ }^{14,36}, n$-butylbenzene ${ }^{13,14,37-44}$ and sec-butylbenzene ${ }^{45}$. Most of these studies were performed above $800 \mathrm{~K}$ and there are very little data about the lowtemperature chemistry of this class of compounds $38-42,44$, which is crucial to well understand the chemistry that occurs in diesel and HCCI engines. In the same way, only a small fraction of these data was obtained at pressures above 1 bar 16,19,26,27,29,38-41, which are more representative of the conditions found in a diesel or an HCCI engine. Furthermore, only a few of these data were obtained in a JSR for ethylbenzene $20,21,25, n$-propylbenzene $29,30,34,35, n$-butylbenzene ${ }^{41,42}$, and $n$-hexylbenzene ${ }^{44}$. Concerning the reactants considered in this paper, JSR experiments were performed for ethylbenzene at $1 \mathrm{~atm}$ and equivalence ratios from 0.25 to $2{ }^{21}$ and at 10 bar for stoichiometric mixtures 20,25 , as well as for $n$-butylbenzene at atmospheric pressure with equivalence ratios of $0.25,1.0$, and $2.0{ }^{42}$, and at 10 bar with equivalence ratios of $0.25,0.5,1.0$, and $1.5^{41}$.

Early studies about the oxidation of alkyl-benzenes enabled a better understanding of the high-temperature chemistry of this class of species. Observations from flow reactor studies 
highlighted the main consumption routes for the reactant 18,28,36,37: (i) abstractions of $\mathrm{H}$-atoms from the alkyl chain forming alkyl radicals decomposing by $\mathrm{C}-\mathrm{C}$ and $\mathrm{C}-\mathrm{H} \beta$-scission; (ii) ipsoadditions of $\mathrm{H}$-atoms and hydroxyl radicals leading to benzene and phenol; (iii) unimolecular initiation by breaking of the benzylic C-C bond yielding benzyl radical. This last reaction has a

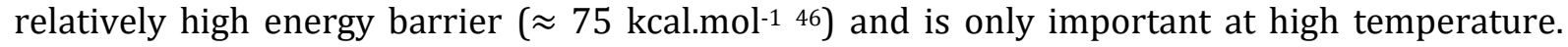
Another interesting observation is that the reactivity of alkylbenzenes depends on the length of the alkyl chain. Indeed, Roubaud et al., who measured ignition delay times of alkyl-benzenes in a rapid compression machine 19,38 , observed that the reactivity increased with the number of carbon atoms in the side alkyl chain. Roubaud et al. also observed that alkylbenzenes, such as $n$ propyl- and $n$-butylbenzenes, presented features of low-temperature reactivity with the observation of a two stage ignition (cool flame) ${ }^{38}$. The presence of a NTC zone was observed in JSR studies for $n$-butylbenzene ${ }^{41,42}$. The modeling study performed by Husson et al. ${ }^{42}$ showed that the addition of resonance-stabilized radicals (also called benzylic radicals) to molecular oxygen played a preponderant role in the low-temperature oxidation chemistry of alkyl-benzene species, because it promoted the low-temperature reactivity through the formation of branching agents (hydroperoxide species). This was confirmed by a latter study about $n$-hexylbenzene in a JSR ${ }^{44}$.

In order to extend the understanding of the low- and high-temperature oxidation chemistries of alkylbenzenes, with a particular attention paid to the effect of the pressure and equivalence ratio, two alkylbenzene model molecules were studied. The oxidation of ethyl- and $n$-butylbenzenes was experimentally investigated for temperatures ranging from 500 to $1100 \mathrm{~K}$, for equivalence ratios of $0.25,1$ and 2, and at pressures from 1 to 10 bar. Comparisons were also made with modelling using the recent model of Yuan et al. ${ }^{25}$ and that of Husson et al. ${ }^{42}$.

\section{Description of the high-pressure jet-stirred reactor}

This study uses a setup including a Jet-Stirred Reactor (JSR) working under isothermal conditions and enabling experiments to be performed at pressures up to 10 bar. This device was developed from the existing JSR that is used by our team to performed oxidation and pyrolysis experiments at pressures close to the atmosphere 47,48 . The 10 bar device was already used to study the oxidation of ethylbenzene at 1 and 6 bar ${ }^{49}$.

\subsection{Description of the JSR for high-pressure experiments}

The design of this reactor was proposed by Villermaux et al. in the 70s 50,51 and was then adapted for kinetic studies. The present reactor consists of a sphere with four nozzles at the center of the reactor. These nozzles are used as gas inlets and provide turbulent gas jets stirring the gas phase. Before entering the heated reactor, the gases flow through an intra-annular preheating zone heated up to the reaction temperature. This is needed to avoid temperature gradients in the gas phase due to cold gases entering the warm gas phase 52 .

The dimensions of the high-pressure JSR were slightly modified (Figure S1 in Supplementary Material) compared to what is used at pressure close to 1 bar. Only the diameter of the spherical part of the reactor was decreased (from 56 to $52 \mathrm{~mm}$ ) to reduce the volume (of about $20 \%$ ) and thus the gas consumption. According to the dynamic ideal gas law, the total flow rate through the reactor is directly proportional to the pressure. Thus a factor of ten in the pressure leads to a factor of ten in the total flow rate if the volume of the reactor is held constant. According to the theory of the jet-stirred reactor $50,51,53$, the decrease of the diameter of the reactor slightly changes the range of residence times.

To resist high pressures, this JSR, which is made of fused silica, was set in a steel vessel so that the inside pressure is the same as the outside pressure. Holes are made in the lower part of the outlet of the reactor to obtain a fast pressure equilibrium between the inside and the outside. An 
auxiliary helium inlet connected to the steel vessel was used to flush the volume between the vessel and the reactor and to avoid the fouling of this volume by gases exiting the JSR.

The heating of the preheating zone and of the reactor is achieved with Thermocoax resistances rolled around them, as for the atmospheric pressure JSR. This heating system allows a fast heating of the reactor and an homogenous temperature as resistances fit well its different parts 54. The temperature is controlled using Eurotherm 3216 controllers with K-type thermocouples. The reaction temperature is measured using an independent K-type thermocouple located in the intra-annular part of the preheater (with its extremity located in a glass finger leaving the center of the spherical part). The uncertainty in the reaction temperature measurement is estimated to $\pm 2 \mathrm{~K}$

Mass flow controllers control gas flow rates whereas the liquid flow rate of fuel is controlled by a Coriolis flow controller. The fuel liquid flow is mixed with the carrier gas flow and evaporated through a heat exchanger before entering the reactor. The fuel is stored in a steel vessel, which is pressurized to feed the Coriolis flow controller. The error in gas flow rates given by the manufacturer is $\pm 0.5 \%$. The accuracy in the fuel flow rate is $\pm 0.2 \%$. Uncertainties in flow rates lead to an error of $\pm 5 \%$ in the residence time $(\tau=2.0 \pm 0.1 \mathrm{~s})$. The pressure in the vessel is controlled by a pressure controller able to maintain the pressure between 0.001 and 10 bar (accuracy of $\pm 0.5 \%$ ).

\subsection{Analytical methodology}

The sampling strategy used with atmospheric pressure JSR (sampling at the outlet of the reactor) could not be applied to the high-pressure JSR because of the large difference of pressure between the reactor and the gas chromatographs. The sampling from the gas phase is thus performed using a fused silica capillary tube (0.20-0.25 $\mathrm{mm}$ internal diameter). The pressure drop in the capillary tube is sufficient to maintain the difference of pressure between the reactor and the downstream analytical part of the apparatus. The residence time in the capillary tube was estimated to $0.1 \mathrm{~ms}$. Note that the use of a sonic probe similar to that used for sampling in flame experiments ${ }^{55}$ was unsuccessfully tested. Two unexpected phenomena were observed in the experimental data obtained using the sonic probe when varying the pressure (see text and Figure S2 in Supplementary Material). This could be due to a change of gas properties and velocities in the probe mainly due to the large pressure drop through it.

The capillary tube is connected to a heated transfer line (length of 2 meters, residence time of about $0.15 \mathrm{~s}$, heated to about $450 \mathrm{~K}$ to avoid condensation) for the transport of reaction products to the four gas chromatographs needed for identifying and quantifying the wide range of detected products from $\mathrm{C}_{1}$ up to $\mathrm{C}_{16}$. The analytical procedure has already been described in previous papers 47 and only its main features are reminded here. The first gas chromatograph is equipped with a Carbosphere packed column and a thermal conductivity detector (carrier gas helium) for the quantification of $\mathrm{O}_{2}$. The second one is fitted with a Plot-Q capillary column and a flame ionization detector preceded by a methanizer enabling the quantification of carbon containing species up to $\mathrm{C}_{6}$. Thanks to the methanizer, it is possible to detect $\mathrm{CO}, \mathrm{CO}_{2}$ and formaldehyde and to improve the sensitivity of larger oxygen containing species (e.g., aldehydes, ketones, cyclic ethers). The third gas chromatograph is equipped with a HP- 5 capillary column and a flame ionization detector. It is used for the quantification of species with more than five carbon atoms. Hydrogen and water are not quantified (the quantification of hydrogen with a thermal conductivity detector is possible but using argon as carrier gas; the quantification of water is difficult using gas chromatography). A fourth gas chromatograph fitted with a massspectrometer detection (GC-MS), which can be fitted with the Plot-Q or the HP-5 capillary column, is used for species identification. 
The calibration of the gas chromatographs was performed by injecting standards (gaseous standards provided by Messer and Air Liquide for $\mathrm{O}_{2}$ and $\mathrm{C}_{1}-\mathrm{C}_{4}$ species and liquid standards for species liquid under ambient conditions, such as the fuel). For the large carbon containing species detected with the flame ionization detector, the method of effective carbon number ${ }^{9}$ was used for the calibration. This method is based on the relative response of carbon atoms in a molecule according to its surroundings (e.g., 1- and 2-heptenes have the same calibration coefficient; the calibration coefficient of $n$-butane is twice that of ethane).

Uncertainties in the mole fraction of the species that are calibrated with standards are estimated to $\pm 5 \%$ and to $\pm 10 \%$ for species calibrated using the effective carbon number method. Formaldehyde could be detected thanks to the methanizer but the related peak had a long tail and the related uncertainty was evaluated to $\pm 15 \%$.

\subsection{Test of the high-pressure JSR device at 1 bar}

To give trust in the experimental data obtained with the recently developed high-pressure device, a comparison is presented between data obtained using the 10 bar JSR and the long-used atmospheric pressure JSR. Both reactors were used at a pressure close to 1 bar. The 1 bar device has already been used for many oxidation and pyrolysis kinetic studies ${ }^{56}$. This test was made with $n$-heptane, a molecule that was investigated in many kinetic studies since it is a primary reference fuel for the gasoline octane rating ${ }^{57}$. The experiments were performed at 825 Torr (1.09 bar), a residence time of $2.0 \mathrm{~s}$, an equivalence ratio of 1 (stoichiometric conditions), an inlet fuel mole fraction of $5 \times 10^{-3}$ (dilution in helium) and at temperatures ranging from 500 to $1100 \mathrm{~K}$.

The two sets of data are presented in Figure S3 given in Supplementary Material, which displays the mole fraction profiles of fuel, oxygen and $\mathrm{C}_{1}-\mathrm{C}_{3}$ products obtained using the two jet-stirred reactors for experiments at 1.09 bar. The agreement between both sets of data is very good. A slight difference is only observed for the fuel reactivity in the temperature range 800-875 K, where it starts again after the end of the negative temperature coefficient phenomenon. In this temperature region, the reactivity is very sensitive to the reaction temperature that is controlled at $\pm 2 \mathrm{~K}$. Another cause could be wall reactions involving $\mathrm{HO}_{2}$ radicals and hydrogen peroxide, which is the main branching agent is this temperature zone 58 .

\section{Study of $n$-heptane oxidation at 10 bars}

The oxidation of $n$-heptane was investigated at 10 bars, a residence time of $2.0 \mathrm{~s}$, an equivalence ratio of 1 , an inlet fuel mole fraction of $1 \times 10^{-3}$ and at temperatures ranging from 500 to $1100 \mathrm{~K}$. Compared to previous JSR experiments performed at 1 bar 9,11 , a lower inlet fuel mole fraction was used to avoid a too strong temperature gradient in the reactor due to the reaction exothermicity.

Figure 1 displays the temperature dependence of the mole fraction of the major species. This figure also displays experimental data obtained by Dagaut et al. 7 under similar conditions except for a residence time of $1 \mathrm{~s}$. Performing experiments at $1 \mathrm{~s}$ would be theoretically possible with our jet-stirred reactor but flow rates would be very large, especially at low temperatures (more than 20 standard liter per minute). These flow rates are not accessible with actual flow controllers and such large flow rates could damage the apparatus, in particular because of the high velocity of the jets inside the reactor $\left(\approx 250 \mathrm{~m} \cdot \mathrm{s}^{-1}\right.$ for $\tau=1 \mathrm{~s}$ at the outlet of a nozzle $)$. As it can be seen in Figure 1, the two sets of experimental data are consistent with a NTC zone between 650 and $750 \mathrm{~K}$. As is can be expected, the reactivity is slightly larger, especially between 700 and $800 \mathrm{~K}$, at a residence time of $2.0 \mathrm{~s}$ as is shown by the mole fraction profile of $n$ heptane. 

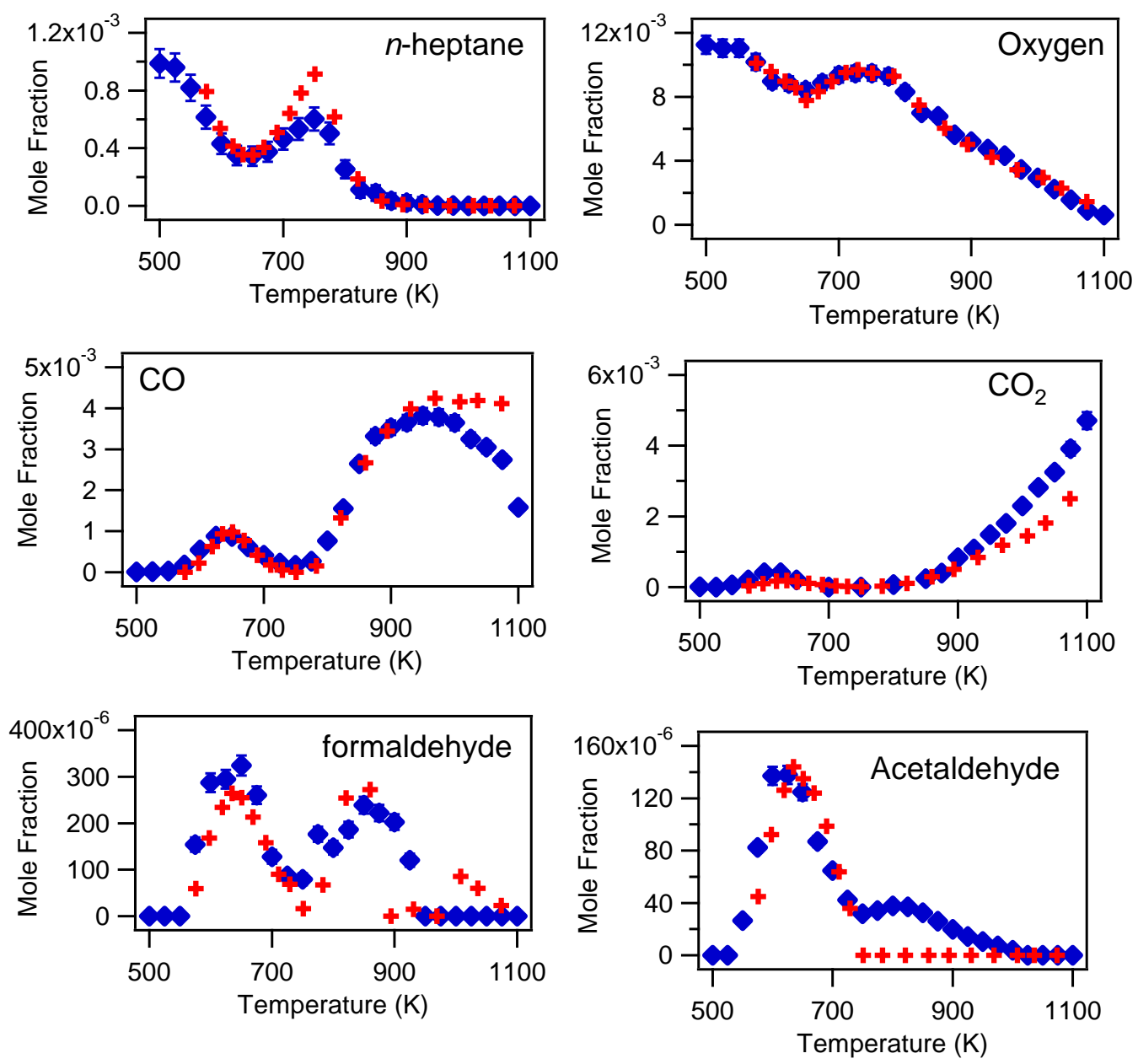

Figure 1: $\boldsymbol{n}$-Heptane oxidation: Comparison between the present experimental temperature dependence of the major species mole fractions in blue (residence time of $2.0 \mathrm{~s}$ and $x_{f u e l}^{\text {inlet }}=$ 0.001 ) and that from literature 7 in red (residence time of $1 \mathrm{~s}$ ) at 10 bar and for stoichiometric mixtures with $x_{\text {fuel }}^{\text {inlet }}=0.001$.

\subsection{Product distribution}

The species quantified during these experiments can be classified as follows:

- Species with the same skeleton as the reactant (typical low-temperature oxidation products from alkanes):

○ $C_{7}$ olefins: 1-, 2- and 3-heptenes,

- $\mathrm{C}_{7}$ ketones: 2- and 3-heptanones,

$\circ \mathrm{C}_{7}$ cyclic ethers: 2-ethyl,5-methyl-tetrahydrofuran (E.M. tetrahydrofuran) and 2-propyl-tetrahydrofuran (P. tetrahydrofuran),

- C 7 diones: 2,4- and 3,5-heptadiones,

- Smaller saturated aldehydes: formaldehyde, acetaldehyde, propanal, butanal, butanone.

- Smaller ketones: acetone, 2-butanone,

- Ethylene oxide,

- Unsaturated aldehydes and ketones: acrolein, methyl-vinyl-ketone, 2-butenal,

- Smaller olefins: ethylene, propene, 1-butene, 1-pentene and 1-hexene,

- Carbon monoxide and carbon dioxide. 
The lower inlet fuel mole fraction used at 10 bar $\left(1 \times 10^{-3}\right)$ compared to that used during our previous 1.09 bar experiments $\left(5.10^{-3}\right)$ explains why a lower number of species has been quantified by gas chromatography than in 9,11). For instance, only two $\mathrm{C}_{7}$ cyclic ethers have been quantified, the furan derivatives, while 9,11 also reported the presence of oxiranes and oxetanes. Note that at 10 bar, acetic and propanoic acids, which were present at 1 bar, could not be seen.

\subsection{Temperature dependence of product mole fractions at 10 bars}

Figure 2 presents the experimental temperature dependence of the mole fractions of all the species quantified in this study. For comparison, this figure includes also the results of a simulation using the model recently developed in Galway and validated on JSR results obtained in Nancy at a pressure close to 1 bar 11 . Figure S4 in supplementary material presents the reaction pathways taken into account in the model of Zhang et al. ${ }^{11}$.

Overall, a good agreement between experimental and computed data can be observed, with especially a correct prediction of the shape of these temperature dependences. However, a notably larger overprediction is observed for acetaldehyde, ethylene oxide, acetone (above 700 $\mathrm{K})$, 2-butanone, butanal, $\mathrm{C}_{7}$ olefins and $\mathrm{C}_{7}$ cyclic ethers compared to modeling of 1 bar results 11 . Note that $\mathrm{C}_{7}$-ketones, such as $\mathrm{C}_{7}$-diones discussed below, are not considered in the model of 11 .

\subsection{Influence of the pressure on fuel conversion and product selectivities}

Figure 3 shows the temperature dependence of the fuel conversion at $1{ }^{9}$ and 10 bar. This figure shows well that the pressure increase significantly enhances the mixture reactivity above $600 \mathrm{~K}$ and decreases the magnitude of the NTC behavior. At $750 \mathrm{~K}$, the conversion rate is close to zero at 800 Torr, while it is still $40 \%$ at 10 bars. The reactivity increase with pressure is because the production of branching agents, ketohydroperoxides, following the two bimolecular $\mathrm{O}_{2}$ additions, are favored.

Figure 3 also displays the product selectivities at these two pressures. The selectivity of a species is defined as the ratio between the mole fraction of the considered species and the sum of mole fractions of all reaction products except diones. If these selectivities would include dione formation, 2,4- and 3,5-heptadione selectivities at $650 \mathrm{~K}$ would be 0.35 and 0.03 , respectively, see discussion hereafter.

Figure 3 shows that at 10 bar the formation of the products formed through the two bimolecular additions to $\mathrm{O}_{2}$, such as carbon oxides and $\mathrm{C}_{1}-\mathrm{C}_{3}$ aldehydes, is favored. On the contrary, the formation of products deriving from unimolecular decomposition pathways preceded or not by an addition to $\mathrm{O}_{2}$, e.g., $\mathrm{C}_{2}, \mathrm{C}_{3}, \mathrm{C}_{4}, \mathrm{C}_{5}$ and $\mathrm{C}_{7}$ alkenes and $\mathrm{C}_{7}$ ketones, is disfavored. As far as the cyclic ether formation is concerned, that of E.M. tetrahydrofuran is enhanced by the pressure increase, while that of P. tetrahydrofuran is reduced.

\subsection{Dione formation}

2,4- and 3,5-heptadiones were quantified by gas chromatography in ${ }^{9}$, however the peak shape of their mole fraction temperature dependence had let to think that a part of their formation, especially below $650 \mathrm{~K}$, should be due to the decomposition of the related ketohydroperoxides in the gas chromatograph line. As is shown in the chromatograms displayed in Figure 4a, 2,4and 3,5-heptadiones are very significant products observed during the present experiments performed at 10 bars. At $575 \mathrm{~K}$, they are the only $\mathrm{C}_{7}$ products, which can be identified. Their importance can also be well seen at $650 \mathrm{~K}$, where their peaks, especially that of 2,4-heptadione, are equivalent to or larger than those of the $C_{7}$ cyclic ethers. 

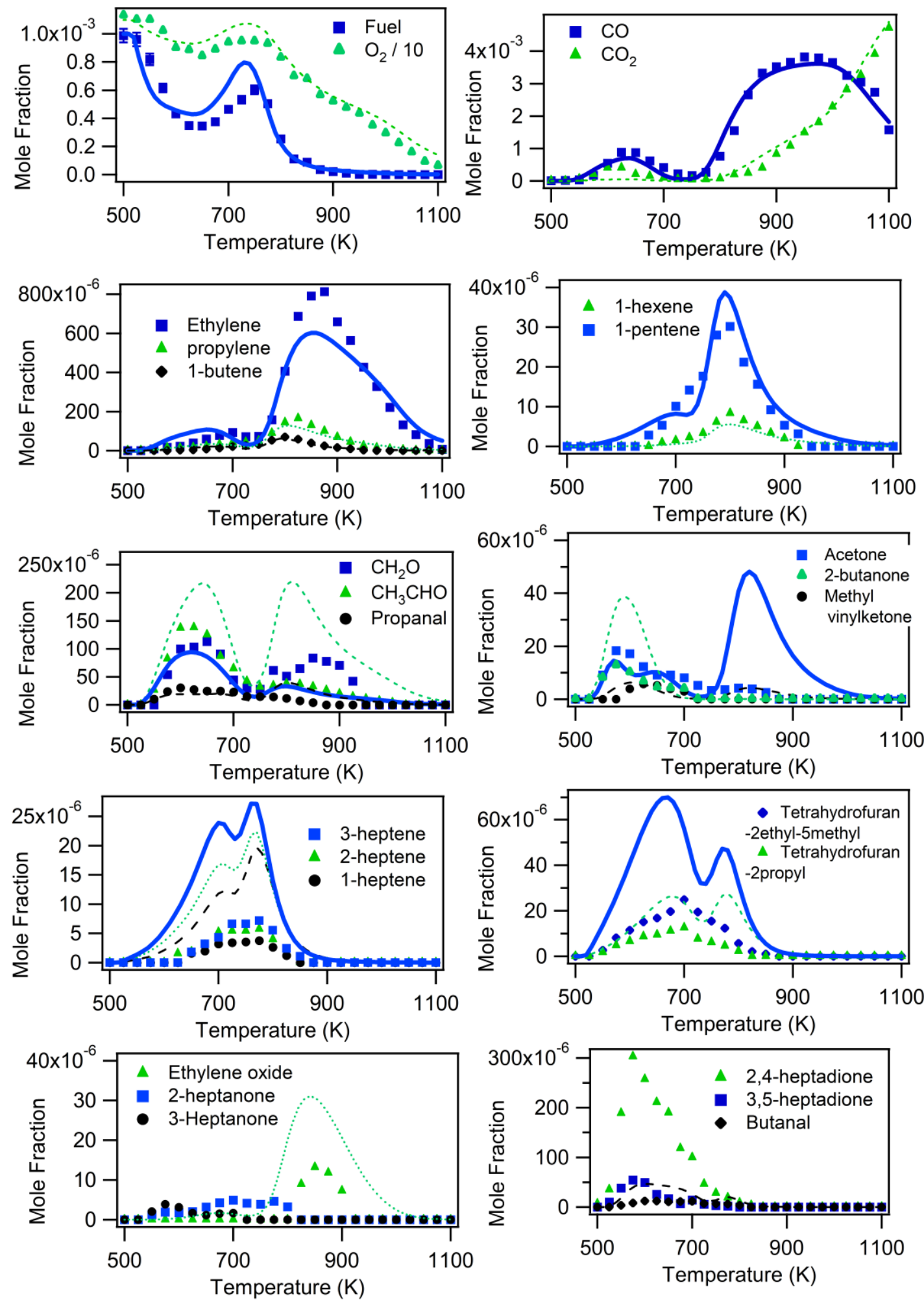

Figure 2: $\boldsymbol{n}$-Heptane oxidation: comparison between the present experimental temperature dependence of the mole fractions of the quantified species and that simulated using the model of Zhang et al. ${ }^{9}$. Points are experiments and lines simulations (residence time of $2.0 \mathrm{~s}$, at 10 bars, for stoichiometric mixtures with $x_{\text {fuel }}^{\text {inlet }}=0.001$. 
n-Heptane
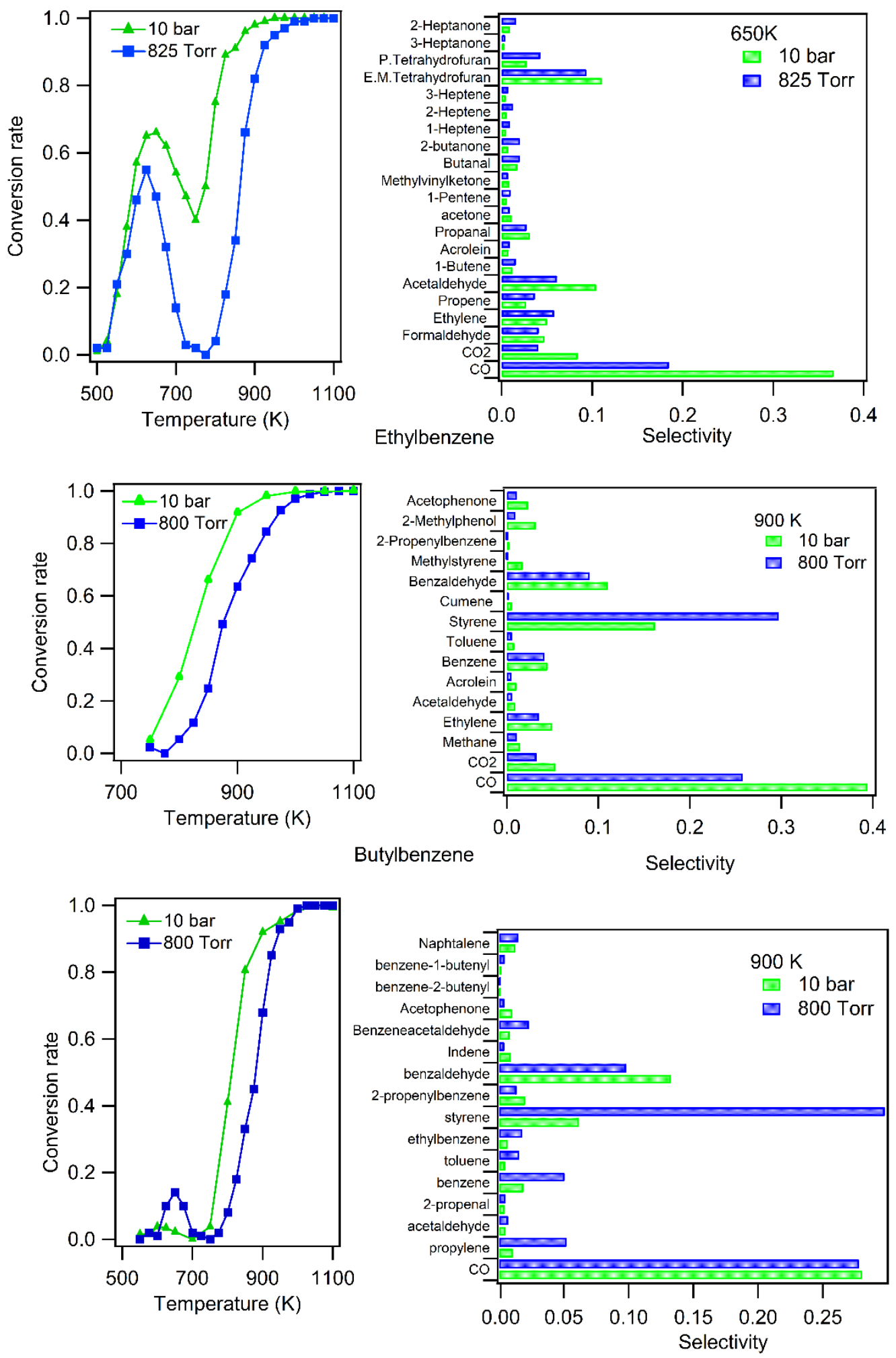

Figure 3: $\boldsymbol{n}$-Heptane, ethylbenzene and $\boldsymbol{n}$-butylbenzene oxidation: Experimental temperature dependence at $\approx 800$ Torr and 10 bars of the conversion and product selectivity for products with a selectivity above $0.3 \%$ (stoichiometric mixtures with inlet fuel mole fractions of $5 \times 10^{-3}$ for $n$-heptane at 825 Torr $^{9}, 1 \times 10^{-3}$ for $n$-heptane at 10 bars, $5 \times 10^{-3}$ for ethylbenzene at 800 Torr $^{21}, 1 \times 10^{-3}$ for ethylbenzene at 10 bar, $4 \times 10^{-3}$ for $n$-butylbenzene at 800 Torr ${ }^{42}$ and $8 \times 10^{-4}$ for $n$-butylbenzene at 10 bars). 


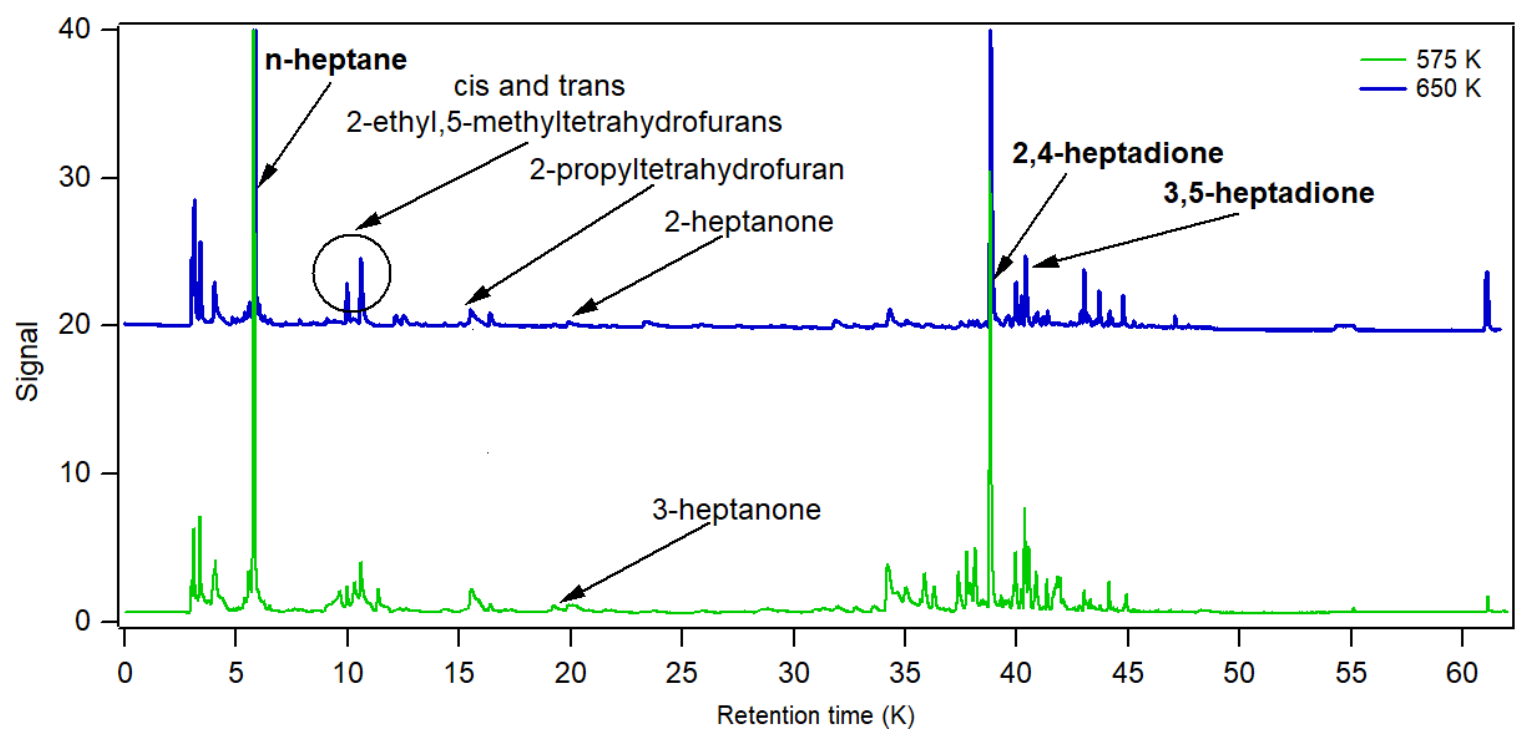

(a)
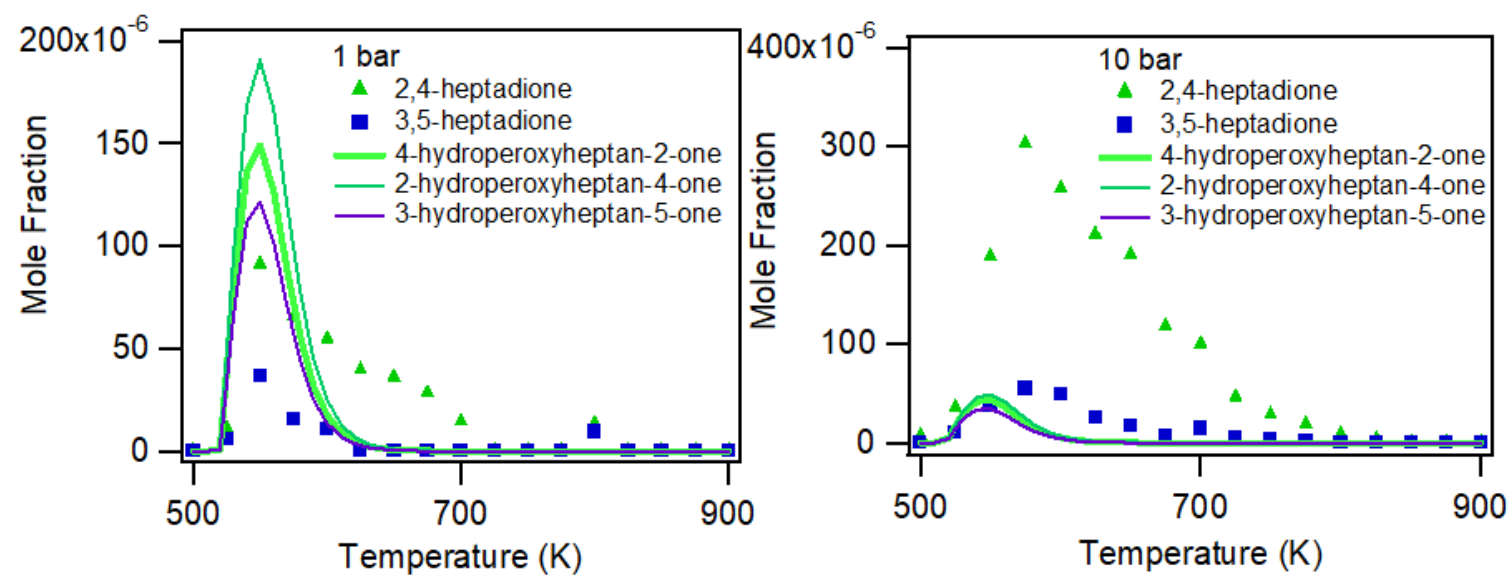

(b)

Figure 4: $\boldsymbol{n}$-Heptane oxidation: (a) Chromatograms obtained with a HP-5 capillary column and (b) experimental temperature dependence of the mole fraction of diones (experimental) and related ketohydroperoxides (modelling using the model of Zhang et al. ${ }^{9}$ ).

Figure $4 \mathrm{~b}$ displays the experimental temperature dependences of dione mole fractions at 800 Torr and 10 bar and compares them to the simulated temperature dependences of ketohydroperoxides (KHPs) mole fractions. The three KHPs with oxygen atoms at the same positions as in diones have been considered. Close to atmospheric pressures and below $650 \mathrm{~K}$, the temperature dependence of dione mole fractions match not so badly that simulated for KHPs. That and the fact that, at $550 \mathrm{~K}$, measured dione mole fractions are lower than simulated KHP mole fractions could indicate that a part of this dione formation can be due to the decomposition of the related ketohydroperoxides in the gas chromatograph line. This is not so true for 2,4-heptadione above $600 \mathrm{~K}$ where KHP decomposition in the analytical line leads probably to a smaller fraction of dione formation. At 10 bars, the picture is quite different. The temperature dependence of dione experimental mole fractions does not really match that simulated for KHPs and corresponds to much higher values, especially for 2,4-heptadione. This indicates that the diones observed do not only derive from KHP decomposition and that the pathway leading to their formation is favored by a pressure increase. As pointed out by Wang et al. ${ }^{59}$, the way of formation of diones is still unclear. This significant pressure dependence can be a clue helping theoreticians unveiling this chemistry. 


\section{Oxidation of ethyl-benzene at pressures up to 10 bars}

The oxidation of ethylbenzene was investigated at a residence time of $2 \mathrm{~s}$ using mixtures diluted in helium. Two sets of experiments were obtained. First, the pressure dependence of species mole fractions at two distinct temperatures $(900$ and $950 \mathrm{~K}$ ) was plotted for stoichiometric mixtures (fuel inlet mole fraction of $5 \times 10^{-3}$ ). Second, the temperature dependence of species mole fractions at 10 bars was followed at three equivalence ratios $(0.25,1$ and 2$)$ with a fuel mole fraction of $1 \times 10^{-3}$. In both cases, comparison with predictions using the model of Yuan et al. 25 are shown.

\subsection{Product distribution}

The following species have been quantified during these experiments:

- Oxygenated aromatic compounds: benzaldehyde, methylphenol (cresol), phenylacetaldehyde, and acetophenone (methylphenylketone).

- Aromatic hydrocarbons: benzene, toluene, styrene, and cumene,

- Small non-aromatic hydrocarbons: methane, ethylene and acetylene,

- Carbon monoxide, carbon dioxide, and acetaldehyde.

Other species have been detected, but in low amounts, below 5 ppm: propene, allene, propyne, 1-butene, and butadiene. All these species were also observed in 21.

\subsection{Effect of varying the pressure from 1 to 10 bar at $\varphi=1$}

The oxidation of ethyl-benzene was studied as a function of the pressure from 1.067 to 10 bars at two temperatures (900 and $950 \mathrm{~K}$ ) under the same operating conditions $\tau=2.0 \mathrm{~s}, \varphi=1$ and $x_{\text {fuel }}^{\text {inlet }}=0.005$ as in ${ }^{21}$ to highlight the sole effect of the pressure on the reactivity and mole fractions of reaction products.

The influence of the pressure on fuel consumption is displayed in Figure 5. A strong effect is observed over the studied pressure range depending on temperature. At $900 \mathrm{~K}$, the fuel consumption increases significantly from 1 to 10 bars. The fuel consumption is significantly higher at $950 \mathrm{~K}$ over the whole pressure range, with the highest reactivity observed at 10 bars. The rate of formation of $\mathrm{CO}_{2}$ keeps significant even at 10 bars. This is due to the conversion of $\mathrm{CO}$ to $\mathrm{CO}_{2}$ through the following bimolecular steps: mainly $\mathrm{CO}+\bullet \mathrm{OH} \rightleftarrows \mathrm{CO}_{2}+\mathrm{H} \bullet$ and to a lesser extent $\mathrm{CO}+\mathrm{HO}_{2} \bullet \rightleftarrows \mathrm{CO}_{2}+\bullet \mathrm{OH}$. The pressure effect on these bimolecular elementary steps involved in the oxidation chemistry of hydrocarbons is highlighted.

Concerning the comparison between the experimental results and modelling, it can be spotted that, while the main trends are reproduced, the overall agreement is less satisfactory when pressure dependences are plotted than for the temperature dependences (see next paragraph), which are more usually displayed in literature papers (e.g. ${ }^{21,25}$ ). This might indicate that pressure effect should be better taken into account in models.

\subsection{Effect of the equivalence ratio ( $\varphi$ ) at 10 bars}

The oxidation of ethyl-benzene was investigated at 10 bars for three equivalence ratios: $0.25,1$ and 2 . The residence time was $2.0 \mathrm{~s}$ and the fuel inlet mole fraction was set to only $1 \times 10^{-3}$ to avoid large gradients of temperature in the gas phase (compared to $5 \times 10^{-3}$ in previous works 21,49 at lower pressures). Note that only a qualitative comparison with data previously obtained at higher pressures can be made because of this difference in fuel inlet mole fractions, which also allows less products to be quantified. 

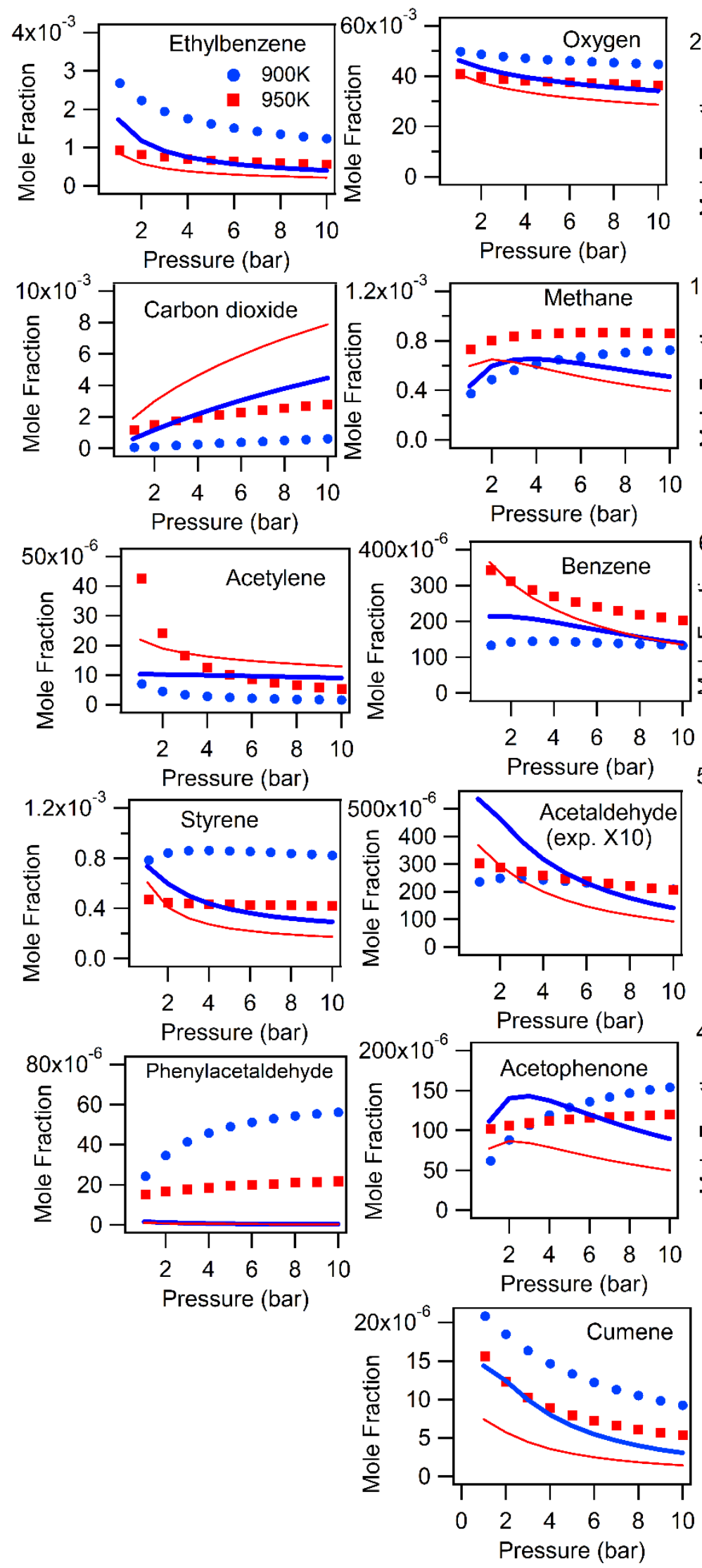
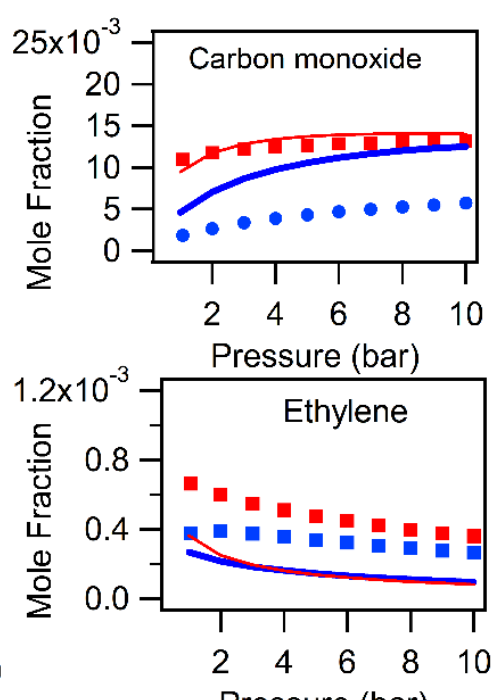

Pressure (bar)

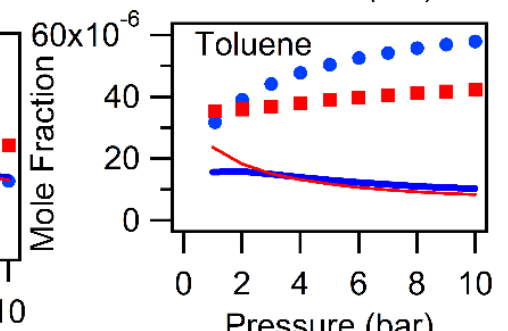

Pressure (bar)
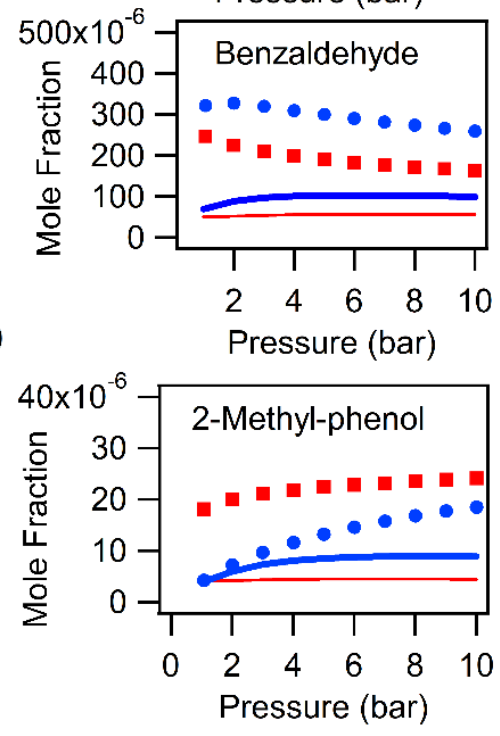

Figure 5: Ethylbenzene oxidation: Experimental pressure dependence of the species mole fractions ethylbenzene from 1.067 to 10 bars at 900 and $950 \mathrm{~K}\left(\tau=2.0 \mathrm{~s}, \boldsymbol{\varphi}=1\right.$ and $x_{\text {fuel }}^{\text {inlet }}=$ 0.005). Symbols are experimental results and lines simulations using the model of 25 . 

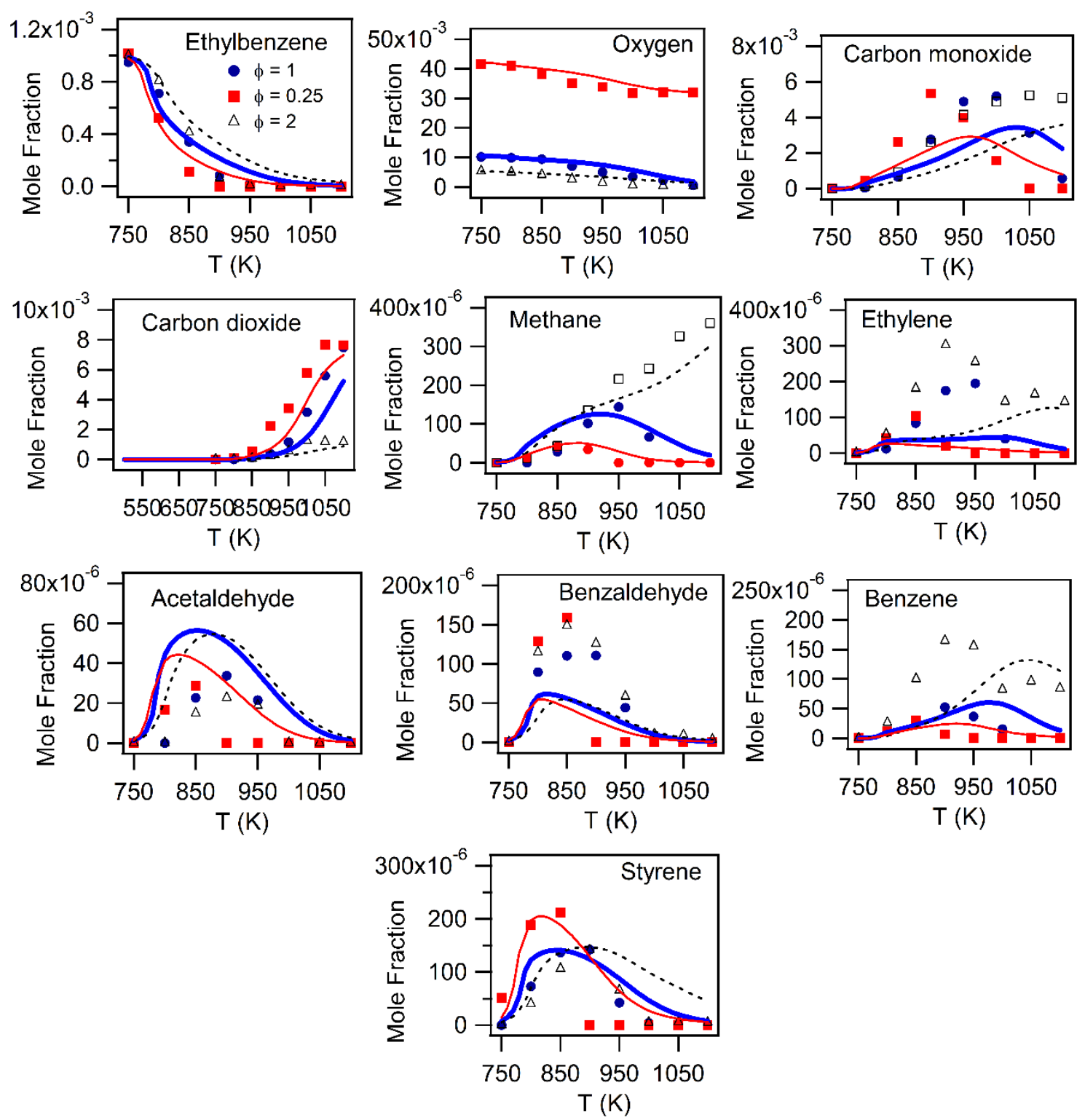

Figure 6: Ethylbenzene oxidation: Experimental and simulated temperature dependence of the species mole fractions at 10 bars for $\varphi=0.25,1$ and $2\left(\tau=2.0 \mathrm{~s}\right.$ and $\left.x_{\text {fuel }}^{\text {inlet }}=0.001\right)$. Symbols are experimental results and lines simulations using the model of 25 .

Figure 6 displays the obtained experimental results. The equivalence ratio has a slight effect in the reactivity in the studied temperature range: there is almost no difference for $\varphi=1$ and $\varphi=2$. A higher reactivity is observed for the lean mixture $(\varphi=0.25)$. These observations differ from what was observed at 1.067 bar: no significant difference for the lean and stoichiometric mixtures and a lower reactivity for the rich mixture ${ }^{21}$. Whatever the equivalence ratio, the consumption of the fuel occurs very early from $750 \mathrm{~K}$, while it was only occurring at $850 \mathrm{~K}$ under atmospheric pressure.

Figure 6 also presents a comparison between these experimental results and simulation using the model of 25 . An overall satisfactory agreement is observed for the three equivalence ratios. Only acetaldehyde is underpredicted whatever $\varphi$ and ethylene at $\varphi=2$ below $950 \mathrm{~K}$. 


\subsection{Influence of the pressure on fuel conversion and product selectivities}

Figure 3 shows the temperature dependence of the fuel conversion at $1{ }^{21}$ and 10 bars and displays the product selectivity at these two pressures. Fuel conversion starts more sharply at high pressure and remains higher over all the temperature range. Concerning the most significant effects on selectivities, the pressure increase favors the formation of carbon monoxide, and disfavors that of styrene.

To explain these selectivity differences, Figure 7 shows a flow rate analysis performed using the model of 25 for the main consumption pathways of ethylbenzene at $900 \mathrm{~K}$ under the conditions of Figure 3. At 10 bars, $\mathrm{H}$-abstractions are slightly favored compared to ipso-additions leading to benzene or phenoxy radicals. One of the radicals obtained by $\mathrm{H}$-abstractions, named $\mathrm{A}_{1} \mathrm{CH}_{2} \mathrm{CH}_{2}$ in the model of 25 , leads to styrene and phenyl radicals (A1), with the styrene formation notably favored at 10 bars. However, the rate analysis also shows that styrene production rate is 2.7 times its rate of consumption at 800 Torr, while it is 1.7 times at 10 bars. This higher consumption rate at high pressure explains the lower selectivity observed at 10 bar.

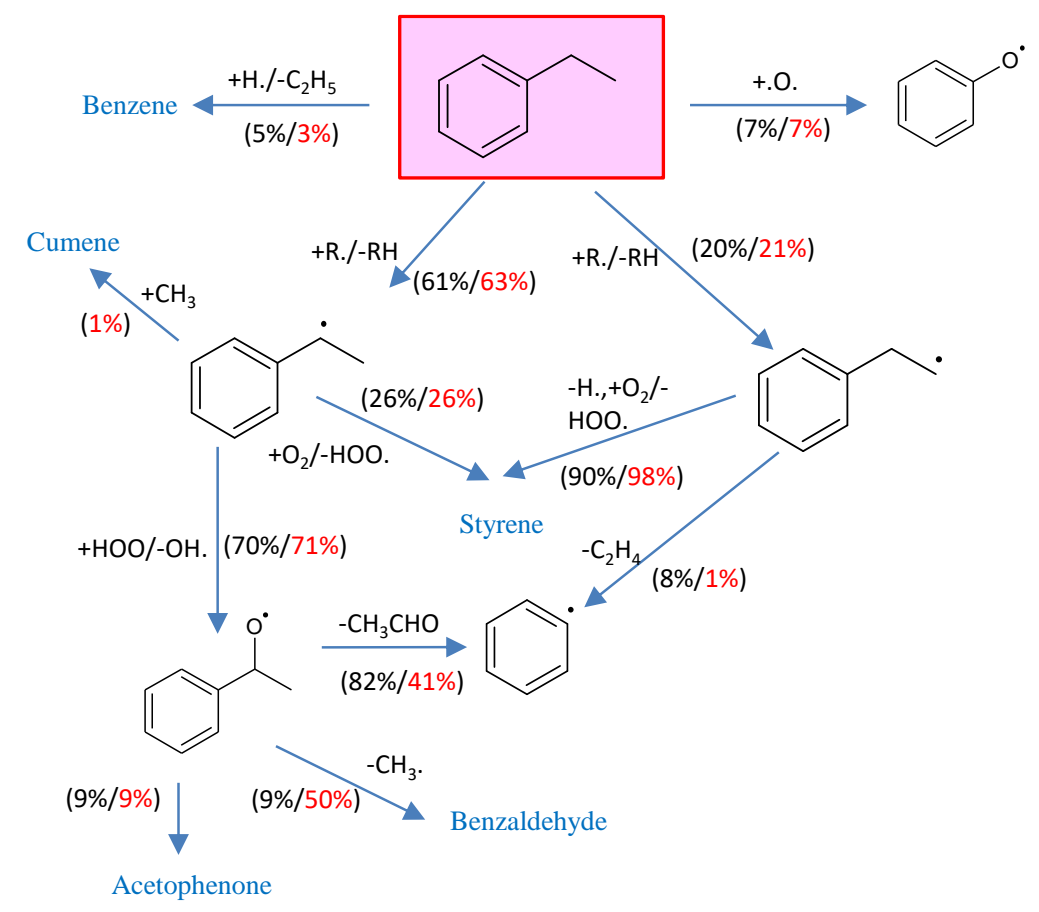

Figure 7: Flow rate analysis for the JSR oxidation of ethylbenzene at $900 \mathrm{~K}, 1$ and 10 bars, for stoichiometric mixtures. The size of the arrows is proportional to that of the flow rates and dotted arrows represent a series of reactions (model of ${ }^{25}$ ).

The second radical obtained by $\mathrm{H}$-abstractions, $\mathrm{A} 1 \mathrm{CHCH}_{3}$, leads to styrene and radical, A1CHOCH 3 , which mainly yields benzaldehyde and acetaldehyde, with the formation of benzaldehyde significantly favored at 10 bars. The fate of $\mathrm{AlCHCH}_{3}$ radical is not much influenced by pressure. Both benzaldehyde and acetaldehyde are a source of CO. A both pressures, benzaldehyde fully reacts by $\mathrm{H}$-abstraction to give A1CO radical, which readily decomposes in phenyl radical and $\mathrm{CO}$. At 10 bars, acetaldehyde fully reacts by $\mathrm{H}$-abstraction to produce $\mathrm{CH}_{3} \mathrm{CO}$ radical yielding methyl radical and $\mathrm{CO}$. At atmospheric pressure, acetaldehyde only partly leads to $\mathrm{CH}_{3} \mathrm{CO}$ radical, but also to $\mathrm{CH}_{2} \mathrm{CHO}$ radical which yields ketene. The lower benzaldehyde formation and the higher decomposition of acetaldehyde to ketene explains the lower CO selectivity observed at the lowest pressure. 


\section{Oxidation of $\boldsymbol{n}$-butyl-benzene at 10 bars}

The oxidation of $n$-butyl-benzene was investigated at 10 bars, at a residence time of $2 \mathrm{~s}$, at three equivalence ratios $\left(0.25,1\right.$ and 2 ) and with a fuel inlet mole fraction of $8 \times 10^{-4}$ (with dilution in helium). As for the two previously studied fuels, the fuel inlet mole fraction was lowered compared to the previous experiments made at 1 bar $\left(4 \times 10^{-3} 4^{42}\right)$ because of a too strong exothermicity. For all the newly obtained experimental data, comparisons with predictions using the model of Husson et al. ${ }^{42}$ are shown.

\subsection{Product distribution}

Reaction products observed in these experiments are the same as those already observed in our previous jet-stirred reactor study performed at atmospheric pressure ${ }^{42}$. They can be classified as follows:

- $\mathrm{C}_{1}-\mathrm{C}_{4}$ hydrocarbons: $\mathrm{CH}_{4}, \mathrm{C}_{2} \mathrm{H}_{2}, \mathrm{C}_{2} \mathrm{H}_{4}, \mathrm{C}_{2} \mathrm{H}_{6}, \mathrm{C}_{3} \mathrm{H}_{6}, 1$-butene, and 1,3-butadiene.

- $\mathrm{C}_{1}-\mathrm{C}_{3}$ oxygenated species: $\mathrm{CO}, \mathrm{CO}_{2}$, acetaldehyde, acrolein, and propanal.

- Aromatic species: benzene, toluene, styrene, ethyl-benzene, indene, indane, 1-propenylbenzene, 1-butenyl-benzene, 2-butenyl-benzene, tetralin, 1,4-dihydro-naphthalene, and naphthalene.

- Oxygenated aromatics: benzaldehyde, phenyl-acetaldehyde, 2-methyl-phenol, and acetophenone.

\subsection{Effect of the equivalence ratio $(\varphi)$ at 10 bar}

The experimental temperature dependences of the mole fractions of reactants and reaction products for three equivalence ratios $(0.25,1,2)$ are displayed in Figures 8 and 9 together with the related simulated ones.

Figure 8 shows that $n$-butyl-benzene is only reactive at low-temperature in the case of the equivalence ratios 0.25 and 1 (lean and stoichiometric conditions). In the previous study at atmospheric pressure, this fuel was also reactive below $800 \mathrm{~K}$ at $\varphi=2$, but the fuel inlet mole fraction was higher $\left(x_{\text {fuel }}^{\text {inlet }}=0.004\right)$. The main reaction products formed in the low-temperature region are mainly aldehydes and unsaturated alkyl-aromatic species:

- aldehydes: acetaldehyde, propanal, benzaldehyde, and phenyl-acetaldehyde

- unsaturated alkyl-aromatics: styrene, 1-butenyl-benzene, and 2-butenyl-benzene

The reactivity in the high-temperature region (above $750 \mathrm{~K}$ ) is very similar for the three equivalence ratios. The only visible differences are in the distribution of reaction products. As it was the case at atmospheric pressure ${ }^{42}$, the formation of hydrocarbons is enhanced in the hightemperature region for the rich conditions $(\varphi=2)$ as it is well visible for methane, ethylene, and benzene. The only hydrocarbons with a significant formation below $700 \mathrm{~K}$ are styrene for $\varphi=$ 0.25 and 1- and 2-butenylbenzenes under lean and stoichiometric conditions. The other products with a significant formation in this temperature zone are acetaldehyde, benzaldehyde and phenylacetaldehyde under lean conditions.

Concerning the comparison between the experimental results and modelling, here also an overall good agreement is observed for the three equivalence ratios. Only the mole fractions of propene, ethylbenzene, 1-propenylbenzene (Figure 8), 2-methylphenol and phenylacetaldehyde (Figure 9) are underpredicted. Note that acetophenone was not considered in the model of Husson et al. 42 . 

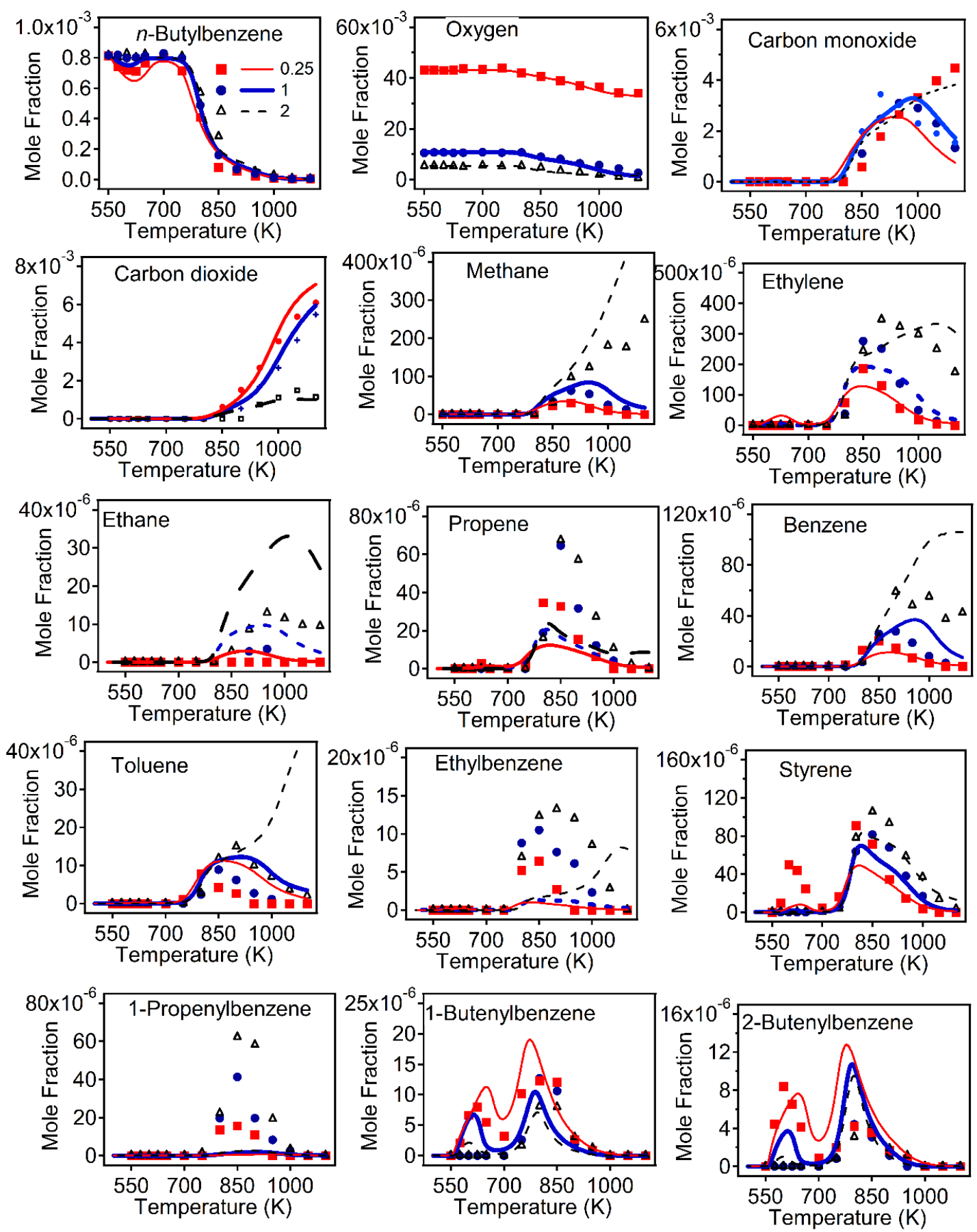

Figure 8: $\boldsymbol{n}$-Butylbenzene oxidation: Experimental temperature dependence of the species (reactants, carbon oxides and hydrocarbons) mole fractions at 10 bars for $\varphi=0.25,1$ and 2 ( $\tau=$ $2.0 \mathrm{~s}$ and $x_{\text {fuel }}^{\text {inlet }}=8 \times 10^{-4}$ ). Symbols are experimental results and lines simulations using the model of 42 . 

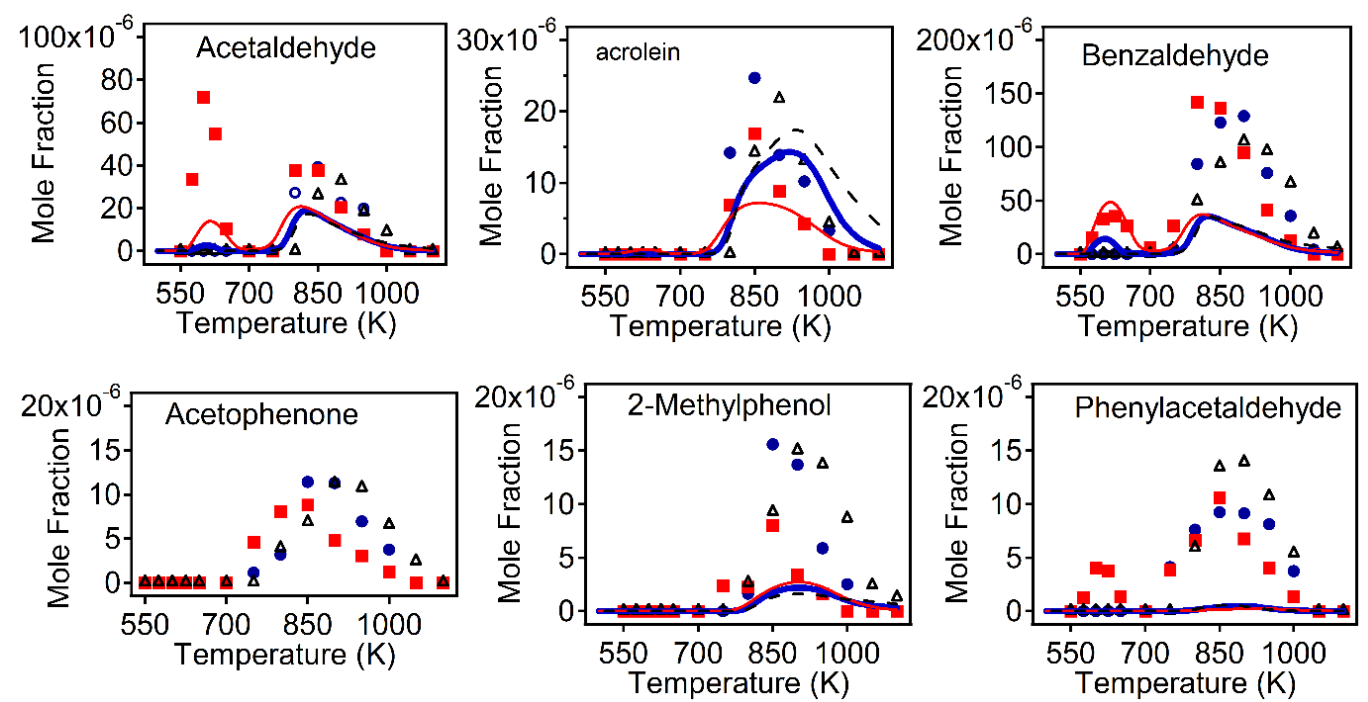

Figure 9: $\boldsymbol{n}$-Butylbenzene oxidation: Experimental temperature dependence of the species (oxygenated hydrocarbons) mole fractions at 10 bars for $\varphi=0.25,1$ and 2 ( $\tau=2.0$ s and $x_{\text {fuel }}^{\text {inlet }}=$

$8 \times 10^{4}$ ). Symbols are experimental results and line simulations using the model of 42 . Acetophenone was not considered in the model.

\subsection{Comparison of ethyl-and n-butylbenzene}

Experiments for the oxidation of ethyl- and $n$-butylbenzene were performed under similar conditions with keeping the carbon content constant at the inlet of the reactor $\left(x_{\text {ethyl-benzene }}^{\text {inlet }}=\right.$ $10^{-3}$ and $x_{n-\text { butyl-benzene }}^{\text {inlet }}=8 \times 10^{-4}$ ) to enable the comparison of both sets of data.

This comparison for the common products for both fuels is displayed in Figure 10 and shows again that ethylbenzene is not reactive at low-temperature whereas $n$-butyl-benzene is slightly reactive (this is more visible in the lower panel in Figure 3), and that ethyl-benzene is slightly less reactive than $n$-butyl-benzene in the temperature range $750-900 \mathrm{~K}$.

As far as product formation is concerned, it can be pointed out that the behaviors of both species are very similar above $800 \mathrm{~K}$ with many common products formed in similar amounts. However, the formation of styrene is favored in the case of ethyl-benzene as it can be easily formed from the fuel radicals by $\beta$-scission and reaction with oxygen molecules. The formation of benzene is also more important for ethylbenzene. The larger mole fractions of 2-phenyl-acetaldehyde are likely linked to these larger mole fractions of benzene. Mole fractions of ethylene and propene are larger for $n$-butylbenzene, likely because of possible $\beta$-scission involving the longer alkyl chain. Mole fractions of toluene and benzaldehyde (likely coming from the oxidation of toluene) are very similar for both fuels.

Below $800 \mathrm{~K}$, the lower reactivity of ethylbenzene compared to that of $n$-butylbenzene is in agreement with previous observations made in a rapid compression machine 19,38. A parallel can be made with what is observed for $n$-alkanes 60 : the reactivity increases with the size of the alkyl chain with an asymptotic behavior for large molecules (above $n$-decane). During their oxidation, alkylaromatics can be seen as an alkyl chain attached to a super atom since the phenyl ring does not react ${ }^{45}$. This is in agreement with the conclusion of Brezinsky et al. ${ }^{37}$ who noted an analogy between alkylaromatics and $n$-alkanes with the same number of carbon atoms in the alkyl chain during their flow reactor experiments. 

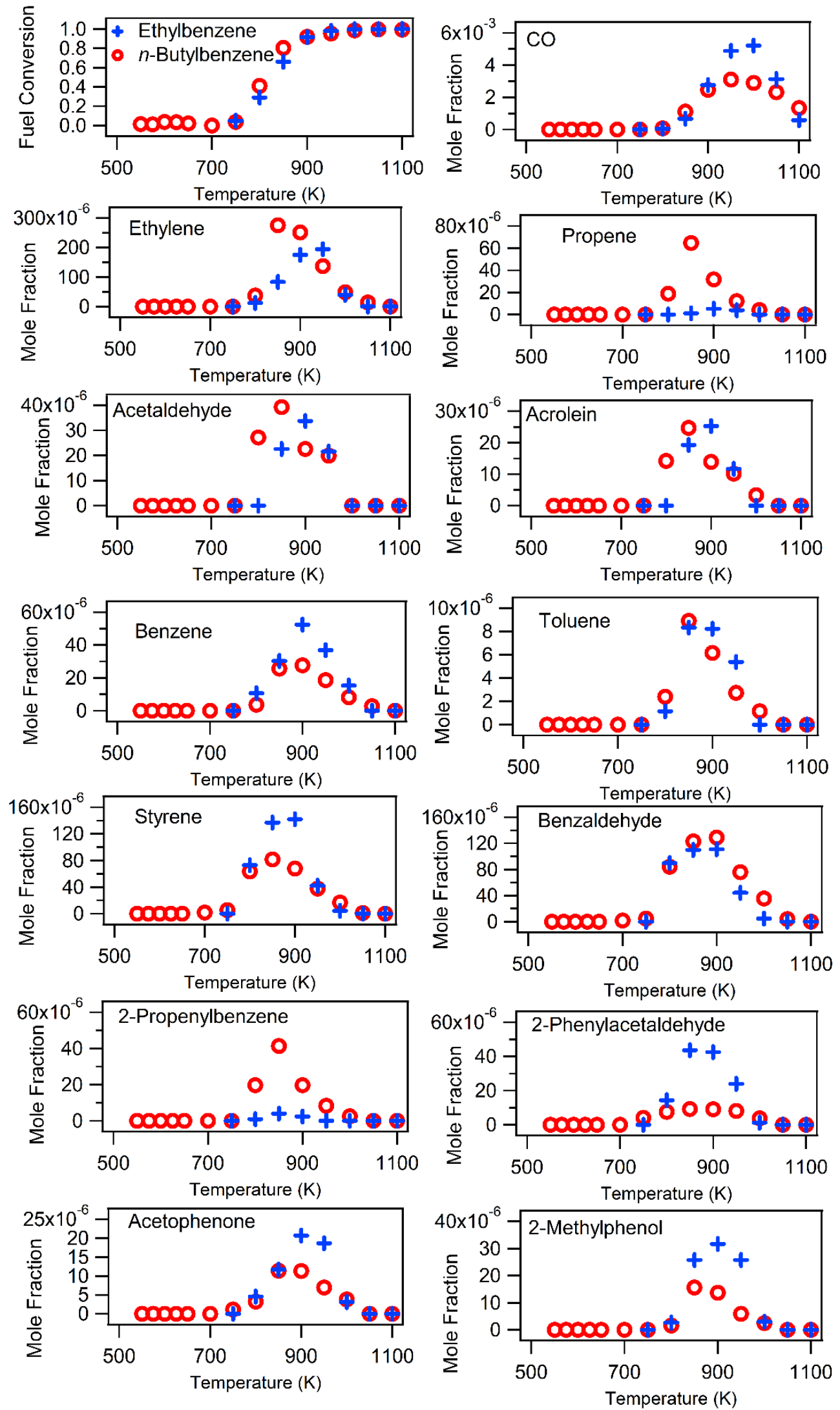

Figure 10: Comparison between ethybenzene and $\boldsymbol{n}$-butylbenzene oxidation: Experimental temperature dependence of major species at 10 bars for $\varphi=1\left(\tau=2.0 \mathrm{~s}\right.$ and $x_{\text {fuel }}^{\text {inlet }}=1 \times 10^{3}$ for ethylbenzene and $=8 \times 10^{4}$ for $n$-butylbenzene). 


\subsection{Influence of the pressure on fuel conversion and product selectivities}

Figure 3 shows the experimental temperature dependences of the fuel conversion at 800 Torr ${ }^{42}$ and 10 bar. Above $700 \mathrm{~K}$, the temperature dependences of the $n$-butylbenzene conversion at both studied pressures are very similar to those of ethylbenzene. At lower temperature, a NTC behavior can be observed at both pressures, but contrary to what is observed for $n$-heptane a higher reactivity would be encountered for the lower pressure. Note that for conversions below $10 \%$, the uncertainty on fuel quantification induces a large uncertainty on the fuel conversion. In addition, as is shown in Figure 8, while it was not the case at 800 Torr, the NTC behavior at 10 bar is well predicted by the model of 42 .

Figure 3 displays the product selectivities at these both pressures and shows that no notable pressure effect can be seen for carbon monoxide. The decrease of styrene selectivity with pressure is even more significant than for ethylbenzene. To help understanding this, Figure 11 presents a flow rate analysis performed for $n$-butylbenzene JSR oxidation at $900 \mathrm{~K}$, at $\varphi=1$ and 10 bars. Styrene is a decomposition product of the resonance stabilized radical (ph\#C4H8X, $\mathrm{C}_{6} \mathrm{H}_{5} \dot{\mathrm{C}} \mathrm{HC}_{3} \mathrm{H}_{7}$, in the model of ${ }^{42}$ ) obtained from $n$-butylbenzene by $\mathrm{H}$-abstraction, which is the dominant radical produced at both pressures. At 800 Torr, this unimolecular decomposition is greatly favored, while at 10 bar it has to compete with the bimolecular reaction with $\mathrm{O}_{2}$ leading to 3-butenylbenzene. This explains the higher selectivity of styrene at low pressure.

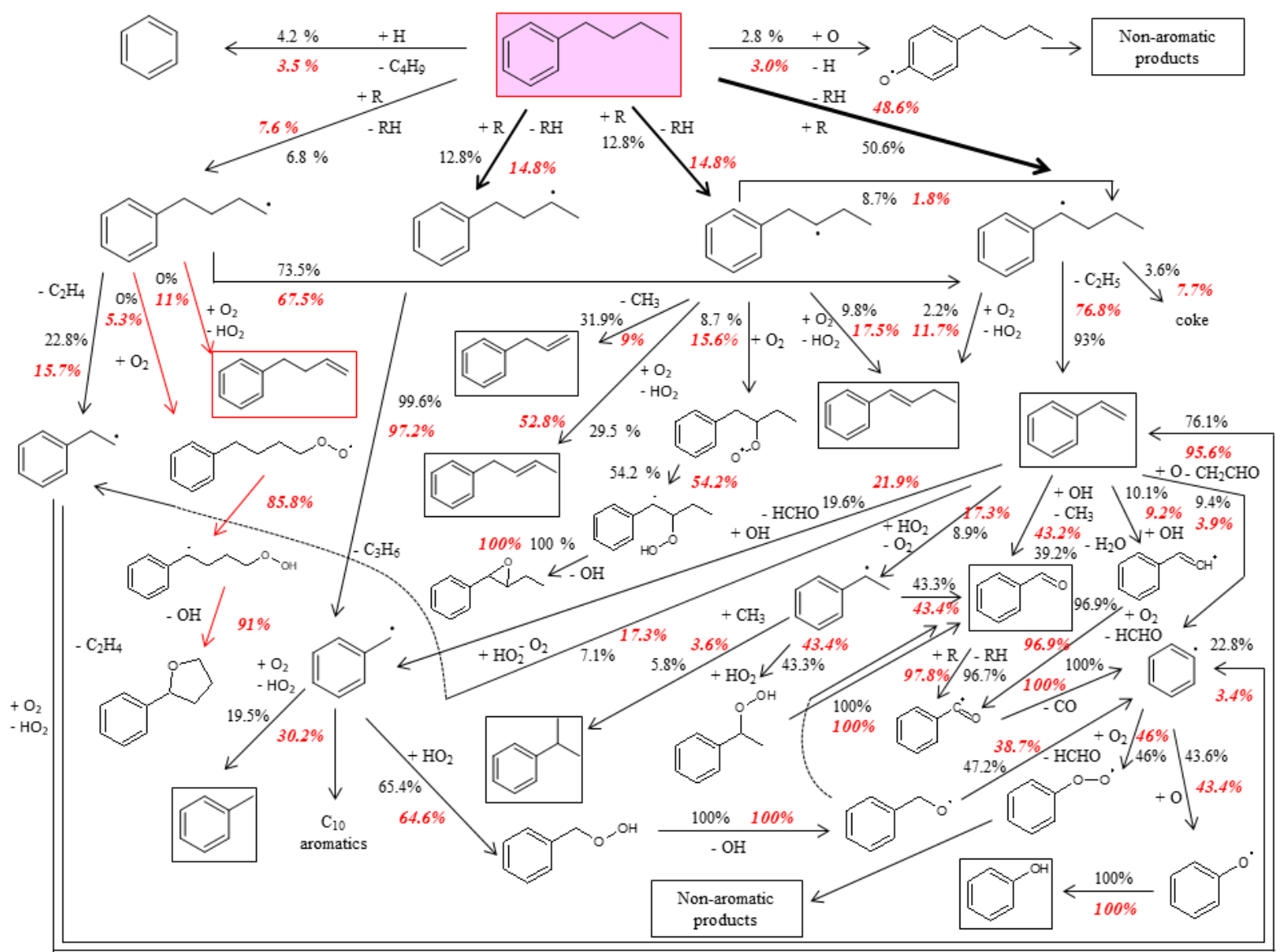

Figure 11: Flow rate analysis for the JSR oxidation of $\boldsymbol{n}$-butylbenzene $(\mathrm{T}=900 \mathrm{~K} ; \mathrm{P}=1.06$ bar; $\varphi=1 ; \tau=2.0 \mathrm{~s} ; \mathrm{x} n$-butylbenzene $=0.4 \%$ ). The numbers in red are obtained under the same operating conditions but at 10 bars. Framed molecules are those experimentally detected

(model of ${ }^{42}$ ). 


\section{Conclusion}

Pressure effect has been a subject experimentally investigated since long by J. Michael et al. ${ }^{61}$. The purpose of the present paper was then better investigating pressure effect during the JSR oxidation of three molecules often considered in surrogates of diesel fuels, $n$-heptane, ethylbenzene and $n$-butylbenzene. This paper describes experimental oxidation data for these molecules representative of diesel fuels.

These data were obtained in a jet-stirred reactor working at pressures up to 10 bars. The JSR setup working at 10 bars was tested against $n$-heptane data: firstly, two sets of data recorded at a pressure close to the atmospheric one using the classic setup and the high pressure setup, providing consistent results; secondly, data recorded at $10 \mathrm{bar}$ and at a residence time of $2.0 \mathrm{~s}$ are consistent with data previously recorded by Dagaut et al. ${ }^{7}$ at a residence of $1.0 \mathrm{~s}$ under the same conditions.

For the three reactants, increasing pressure increases reactivity over all the studied temperature range, except seemingly for $n$-butylbenzene below $700 \mathrm{~K}$. For the three molecules, the results are shown to be consistent with modelling using literature models for the major species with more deviations noted for minor ones. For $n$-heptane, an unexpected important formation of diones, mainly 2,4-heptadione, has been especially observed at 10 bars. A part of the observed diones could be formed from the decomposition of fragile ketohydroperoxides, especially at lowtemperature, and further investigations with advanced sampling and analytical techniques (e.g., molecular beam and time of flight mass spectrometry) are needed to confirm their mole fraction profiles. For alkylbenzenes, the pressure increase disfavors the formation of styrene and promotes that of benzaldehyde.

\section{References}

1. Farrell JT, Cernansky NP, Dryer FL, Law CK, Friend DG, Hergart CA, et al. Development of an Experimental Database and Kinetic Models for Surrogate Diesel Fuels. Warrendale, PA: SAE International; 2007.

2. Pitz WJ, Mueller CJ. Recent progress in the development of diesel surrogate fuels. Prog Energy Combust Sci 2011;37:330-350.

3. Mueller CJ, Cannella WJ, Bruno TJ, Bunting B, Dettman HD, Franz JA, et al. Methodology for Formulating Diesel Surrogate Fuels with Accurate Compositional, Ignition-Quality, and Volatility Characteristics. Energy Fuels 2012;26:3284-3303.

4. Battin-Leclerc F. Detailed chemical kinetic models for the low-temperature combustion of hydrocarbons with application to gasoline and diesel fuel surrogates. Prog Energy Combust Sci 2008;34:440-498.

5. Sarathy SM, Farooq A, Kalghatgi GT. Recent progress in gasoline surrogate fuels. Prog Energy Combust Sci 2018;65:67-108.

6. Dagaut P, Reuillon M, Cathonnet M. High pressure oxidation of liquid fuels from low to high temperature. 1. n-Heptane and iso-octane. Combust Sci Technol 1994;95:233-260.

7. Dagaut $\mathrm{P}$, Reuillon M, Cathonnet M. Experimental study of the oxidation of n-heptane in a jet stirred reactor from low to high temperature and pressures up to $40 \mathrm{~atm}$. Combust Flame 1995;101:132-140. 
8. Ciajolo A, D'Anna A. Controlling steps in the low-temperature oxidation of n-heptane and iso-octane. Combust Flame 1998;112:617-622.

9. Herbinet O, Husson B, Serinyel Z, Cord M, Warth V, Fournet R, et al. Experimental and modeling investigation of the low-temperature oxidation of n-heptane. Combust Flame 2012;159:3455-3471.

10. Wang Z, Chen B, Moshammer K, Popolan-Vaida DM, Sioud S, Shankar VSB, et al. n-Heptane cool flame chemistry: Unraveling intermediate species measured in a stirred reactor and motored engine. Combust Flame 2018;187:199-216.

11. Zhang K, Banyon C, Bugler J, Curran HJ, Rodriguez A, Herbinet O, et al. An updated experimental and kinetic modeling study of n-heptane oxidation. Combust Flame 2016;172:116-135.

12. Hakka HM, Cracknell RF, Pekalski A, Glaude P-A, Battin-Leclerc F. Experimental and modeling study of ultra-rich oxidation of n-heptane. Fuel 2015;144:358-368.

13. Burgoyne JH. The Combustion of Aromatic and Alicyclic Hydrocarbons. I. The Slow Combustion of Benzene, Toluene, Ethylbenzene, n-Propylbenzene, n-Butylbenzene, oXylene, m-Xylene, p-Xylene and Mesitylene. Proc R Soc Math Phys Eng Sci 1937;161:48-67.

14. Salooja KC. Studies of combustion processes leading to ignition of aromatic hydrocarbons. Combust Flame 1965;9:121-129.

15. Scott M, Walker RW. Addition of toluene and ethylbenzene to mixtures of $\mathrm{H} 2$ and $\mathrm{O} 2$ at 773 K. Combust Flame 2002;129:365-377.

16. Shen H-PS, Oehlschlaeger MA. The autoignition of $\mathrm{C} 8 \mathrm{H} 10$ aromatics at moderate temperatures and elevated pressures. Combust Flame 2009;156:1053-1062.

17. Venkat C, Brezinsky K, Glassman I. High temperature oxidation of aromatic hydrocarbons. Symp Int Combust 1982;19:143-152.

18. Litzinger TA, Brezinsky K, Glassman I. The oxidation of ethylbenzene near 1060K. Combust Flame 1986;63:251-267.

19. Roubaud A, Minetti R, Sochet LR. Oxidation and combustion of low alkylbenzenes at high pressure: comparative reactivity and auto-ignition. Combust Flame 2000;121:535-541.

20. Pengloan G. Etude cinétique de l'oxydation de composés aromatiques : application à la formation de polluants dans les moteurs automobiles. January 2001.

21. Husson B, Ferrari M, Herbinet O, Ahmed SS, Glaude P-A, Battin-Leclerc F. New experimental evidence and modeling study of the ethylbenzene oxidation. Proc Combust Inst 2013;34:325-333.

22. Ergut A, Levendis YA, Richter H, Howard JB, Carlson J. The effect of equivalence ratio on the soot onset chemistry in one-dimensional, atmospheric-pressure, premixed ethylbenzene flames. Combust Flame 2007;151:173-195.

23. Li Y, Tian Z, Zhang L, Yuan T, Zhang K, Yang B, et al. An experimental study of the rich premixed ethylbenzene flame at low pressure. Proc Combust Inst 2009;32:647-655. 
24. Marshall SP, Taylor S, Stone CR, Davies TJ, Cracknell RF. Laminar burning velocity measurements of liquid fuels at elevated pressures and temperatures with combustion residuals. Combust Flame 2011;158:1920-1932.

25. Yuan W, Li Y, Pengloan G, Togbé C, Dagaut P, Qi F. A comprehensive experimental and kinetic modeling study of ethylbenzene combustion. Combust Flame 2016;166:255-265.

26. Darcy D, Tobin CJ, Yasunaga K, Simmie JM, Würmel J, Metcalfe WK, et al. A high pressure shock tube study of n-propylbenzene oxidation and its comparison with n-butylbenzene. Combust Flame 2012;159:2219-2232.

27. Gudiyella S, Brezinsky K. High pressure study of n-propylbenzene oxidation. Combust Flame 2012;159:940-958.

28. Litzinger TA, Brezinsky K, Glassman I. Reactions of N-Propylbenzene During Gas Phase Oxidation. Combust Sci Technol 1986;50:117-133.

29. Marchal A. Etude de la contribution des familles chimiques constitutives des gazoles a la formation de polluants non reglementes. January 1997.

30. Dagaut P, Ristori A, El Bakali A, Cathonnet M. Experimental and kinetic modeling study of the oxidation of n-propylbenzene. Fuel 2002;81:173-184.

31. Wang Z, Li Y, Zhang F, Zhang L, Yuan W, Wang Y, et al. An experimental and kinetic modeling investigation on a rich premixed n-propylbenzene flame at low pressure. Proc Combust Inst 2013;34:1785-1793.

32. Ji C, Dames E, Wang H, Egolfopoulos FN. Propagation and extinction of benzene and alkylated benzene flames. Combust Flame 2012;159:1070-1081.

33. Hui X, Das AK, Kumar K, Sung C-J, Dooley S, Dryer FL. Laminar flame speeds and extinction stretch rates of selected aromatic hydrocarbons. Fuel 2012;97:695-702.

34. Yuan W, Li Y, Dagaut P, Wang Y, Wang Z, Qi F. A comprehensive experimental and kinetic modeling study of n-propylbenzene combustion. Combust Flame 2017;186:178-192.

35. Liu Y-X, Wang B-Y, Weng J-J, Yu D, Richter S, Kick T, et al. A wide-range experimental and modeling study of oxidation and combustion of n-propylbenzene. Combust Flame 2018;191:53-65.

36. Litzinger TA, Brezinsky K, Glassman I. Gas-phase oxidation of isopropylbenzene at high temperature. J Phys Chem 1986;90:508-513.

37. Brezinsky K, Linteris GT, Litzinger TA, Glassman I. High temperature oxidation of n-alkyl benzenes. Symp Int Combust 1988;21:833-840.

38. Roubaud A, Lemaire O, Minetti R, Sochet LR. High pressure auto-ignition and oxidation mechanisms of o-xylene, o-ethyltoluene, and n-butylbenzene between 600 and $900 \mathrm{~K}$. Combust Flame 2000;123:561-571.

39. Ribaucour M, Roubaud A, Minetti R, Sochet LR. The low-temperature autoignition of alkylaromatics: Experimental study and modeling of the oxidation of n-butylbenzene. Proc Combust Inst 2000;28:1701-1707. 
40. Crochet M. Adéquation moteurs propres-carburants en combustion homogène: Étude expérimentale en machine à compression rapide et modélisation de carburants modèles types gazoles en milieu ultra-pauvre. 2008.

41. Diévart $\mathrm{P}$, Dagaut $\mathrm{P}$. The oxidation of n-butylbenzene: Experimental study in a JSR at $10 \mathrm{~atm}$ and detailed chemical kinetic modeling. Proc Combust Inst 2011;33:209-216.

42. Husson B, Bounaceur R, Tanaka K, Ferrari M, Herbinet O, Glaude PA, et al. Experimental and modeling study of the oxidation of n-butylbenzene. Combust Flame 2012;159:13991416.

43. Pousse E, Glaude PA, Fournet R, Battin-Leclerc F. A lean methane premixed laminar flame doped with components of diesel fuel: I. n-Butylbenzene. Combust Flame 2009;156:954974.

44. Battin-Leclerc F, Warth V, Bounaceur R, Husson B, Herbinet O, Glaude P-A. The oxidation of large alkylbenzenes: An experimental and modeling study. Proc Combust Inst 2015;35:349356.

45. Zhang Y, Mei B, Cao C, Zhang X, Yuan W, Yang J, et al. Experimental and kinetic modeling investigation on sec-butylbenzene combustion: Flow reactor pyrolysis and laminar flame propagation at various pressures. Combust Flame 2020;211:18-31.

46. Baulch D, Cobos C, Cox R, Esser C, Frank P, Just T, et al. Evaluated kinetic data for combustion modeling. J Phys Chem Ref Data 1992;21:411-734.

47. Rodriguez A, Frottier O, Herbinet O, Fournet R, Bounaceur R, Fittschen C, et al. Experimental and Modeling Investigation of the Low-Temperature Oxidation of Dimethyl Ether. J Phys Chem A 2015;119:7905-7923.

48. Rodriguez A, Herbinet O, Wang Z, Qi F, Fittschen C, Westmoreland PR, et al. Measuring hydroperoxide chain-branching agents during n-pentane low-temperature oxidation. Proc Combust Inst. https://doi.org/10.1016/j.proci.2016.05.044.

49. Herbinet $\mathrm{O}$, Husson B, Le Gall H, Battin-Leclerc F. Comparison study of the gas-phase oxidation of alkylbenzenes and alkylcyclohexanes. Chem Eng Sci 2015;131:49-62.

50. Matras D, Villermaux J. Un réacteur continu parfaitement agité par jets gazeux pour l'étude cinétique de réactions chimiques rapides. Chem Eng Sci 1973;28:129-137.

51. David R, Matras D. Rules for construction and extrapolation of reactors self-stirred by gas jets. Can J Chem Eng 1975;53:297-300.

52. Azay P, Côme G-M. Temperature Gradients in a Continuous Flow Stirred Tank Reactor. Ind Eng Chem Process Des Dev 1979;18:754-756.

53. Herbinet O, Dayma G. Jet-Stirred Reactors. In: Battin-Leclerc F, Simmie JM, Blurock E, editors Cleaner Combustion. Green Energy and Technology. Springer London, 2013;183210.

54. Azay P, Marquaire PM, Pommier P, Scacchi G. A versatile oven with very little thermal inertia. J Chem Educ 1981;58:441. 
55. Gueniche HA, Glaude PA, Dayma G, Fournet R, Battin-Leclerc F. Rich methane premixed laminar flames doped with light unsaturated hydrocarbons: I. Allene and propyne. Combust Flame 2006;146:620-634.

56. Herbinet O, Battin-Leclerc F. Progress in Understanding Low-Temperature Organic Compound Oxidation Using a Jet-Stirred Reactor. Int J Chem Kinet 2014;46:619-639.

57. Pitz WJ, Cernansky NP, Dryer FL, Egolfopoulos FN, Farrell JT, Friend DG, et al. Development of an Experimental Database and Chemical Kinetic Models for Surrogate Gasoline Fuels. Warrendale, PA: SAE International; 2007.

58. Bahrini C, Morajkar P, Schoemaecker C, Frottier O, Herbinet O, Glaude P-A, et al. Experimental and modeling study of the oxidation of $n$-butane in a jet stirred reactor using cw-CRDS measurements. Phys Chem Chem Phys 2013;15:19686-19698.

59. Wang Z, Herbinet O, Hansen N, Battin-Leclerc F. Exploring hydroperoxides in combustion: History, recent advances and perspectives. Prog Energy Combust Sci 2019;73:132-181.

60. Westbrook CK, Pitz WJ, Herbinet O, Curran HJ, Silke EJ. A comprehensive detailed chemical kinetic reaction mechanism for combustion of n-alkane hydrocarbons from n-octane to nhexadecane. Combust Flame 2009;156:181-199.

61. Michael JV, Osborne DT, Suess GN. Reaction H+C2H4: Investigation into the effects of pressure, stoichiometry, and the nature of the third body species. J Chem Phys 1973;58:2800-2806. 